\title{
The Evaluation Standard and Example Analysis of the Professional Practice in the Talent Training of IoT Specialty
}

\author{
Henghua Shi ${ }^{1, a}$, Baoping $\mathrm{Han}^{1, b^{*}}$ and Chengkui Guo ${ }^{1, \mathrm{c}}$
}

${ }^{1}$ School of Computer and Information Engineering, Beijing University of Agriculture, Beijing, China

ahenghuashi@163.com, bhbp@bac.edu.cn, ${ }^{c}$ gxk@bac.edu.cn

"The corresponding author

Keywords: Internet of Things; Professional Practice; Evaluation Standard; Evaluation Index System; Talent Training

\begin{abstract}
With the development of information technology, Internet of things(IoT) technology has been applied to many fields such as agricultural field, industrial field, and etc al. More and more domestic colleges and universities have carry out the training of Internet of things specialty. Professional practice is an important aspect of the talent training of the Internet of things specialty, and lacks the corresponding professional practice evaluation standards. Combined with the training mode of " $3+1$ " talents of professional practice and content of domestic universities, we propose the evaluation standard based on the evaluation index system of Internet of things specialty, and analyze the specific examples.
\end{abstract}

\section{物联网工程专业人才培养中专业实践评价标准与}

\section{示例分析}

\author{
石恒华，韩宝平，郭成魁
}

北京农学院计算机与信息工程学院, 北京 中国

摘要：随着信息技术的不断变革发展，物联网(IoT)技术被应用到农业、工业等许多的领域。越来越多的院校开展物联 网工程专业人才的培养工作。专业实践作为物联网工程专业人才培养的一个重要方面，缺少相应的专业实践评价标准。结合 国内高校推行的“ $3+1$ ”人才培养模式和专业实践内容，以专业实践评价指标体系为基础，提出物联网工程专业人才实践评价 标准，并进行了具体的示例分析。

关键词：物联网；专业实践；评价标准；评价指标体系；人才培养

\section{1 前言}

从当前信息类人才的需求和培养角度，结合国内高校推行的 “ $3+1 ”$ 人才培养模式[1] [2]，通常将最 后一个学年作为专业实践 [3] [4] [5]。其中, 信息类人才培养的专业实践内容可以分为就业、创业、升学 三个方向。物联网工程专业人才培养 [6]作为信息类人才培养的一个重要组成部分，从专业实践内容方面 也可以分为就业、创业、升学三个方向, 但是在物联网工程专业人才的专业实践中, 应该选取哪些评价指 标进行实际评价, 需要进一步进行深入研究和分析。

本文基于已有的信息类人才专业实践效果评价指标体系，针对物联网工程专业人才培养的特点，对就 业、创业、升学三个方向, 提出了每个方向的具体评价标准, 并对具体示例进行了深入分析, 为物联网工 
程专业实践效果的评价提供基础依据。

\section{2 专业实践效果评价标准}

近些年，通过国内高校 “ $3+1 ”$ 信息类人才培养模式的实施 [7] [8] [9]，取得了良好的就业效果。大 部分本科生毕业生选择这个方向, 按照学校的统一安排, 到企业进行实习培训和顶岗等作为 “ $3+1$ ” 中最 后一年的安排。其中, 有一部分毕业生会留在对应的实践企业工作, 更多的毕业生会重新进行就业企业的 选择。同时, 参加就业方向专业实践的本科生毕业生中, 也有人在毕业时选择创业和进行升学。除了就业 方向以外, 随着国家 “大众创业、万众创新” 政策的实施, 部分本科生毕业后选择创业。同时, 随着社会 对信息类人才需求层次的不断提供, 学历成为企业衡量人才的一个重要标准。越来越多的本科生选择升学, 提升个人的知识和能力水平，为未来获得更好工作岗位奠定基础。

物联网工程专业作为信息类专业的一个重要组成部分, 其人才培养中也适于采用信息类人才培养的各 类方式。在物联网工程专业人才专业实践效果评价中，将结合国内高校推行的 “ $3+1$ ” 人才培养模式和专 业实践内容, 以信息类专业实践评价指标体系为基础 $[10]$, 选取出就业、创业、升学三个方向专业实践评 价指标, 作为物联网工程专业人才的专业实践评价指标, 并定义对应函数变量, 如表 1 、表 2 、表 3 所示。

\section{表 1 信息类人才就业方向专业实践效果评价指标}

\begin{tabular}{|c|c|c|c|c|c|c|c|}
\hline 一级指标 & \multicolumn{3}{|c|}{ 就业率 } & \multicolumn{4}{|c|}{ 创业、升学、其他情况率 } \\
\hline 对应函数 & \multicolumn{3}{|c|}{ A } & \multicolumn{4}{|c|}{ B、C、D } \\
\hline \multirow[t]{2}{*}{ 二级指标 } & 双专就业 & 通专就业率 & 其他就业 & 隐性就业 & 失业率 & 创业率 & 升学率 \\
\hline & 率 & & 率 & 率 & & & \\
\hline 对应函数 & A1 & A 2 & $\mathrm{~A} 3$ & D1 & D2 & B & $\mathrm{C}$ \\
\hline 对应系数 & M1 & M2 & M3 & M4 & M5 & 0 & 0 \\
\hline
\end{tabular}

表 2 信息类人才创业方向专业实践效果评价指标

\begin{tabular}{lcccccc}
\hline 一级指标 & \multicolumn{1}{c}{ 创业率 } & \multicolumn{4}{c}{ 就业、升学、其他情况率 } \\
\hline 对应函数 & & $\mathrm{B}$ & \multicolumn{4}{c}{$\mathrm{A} 、 \mathrm{C} 、 \mathrm{D}$} \\
二级指标 & 个人创业率 & 参加团队创业率 & 隐性就业率 & 失业率 & 就业率 & 升学率 \\
对应函数 & $\mathrm{B} 1$ & $\mathrm{~B} 2$ & $\mathrm{D} 1$ & $\mathrm{D} 2$ & $\mathrm{~A}$ & $\mathrm{C}$ \\
对应系数 & $\mathrm{N} 1$ & $\mathrm{~N} 2$ & $\mathrm{~N} 3$ & $\mathrm{~N} 4$ & 0 & 0 \\
\hline
\end{tabular}

表 3 信息类人才升学方向专业实践效果评价指标

\begin{tabular}{lcccccc}
\hline 一级指标 & \multicolumn{2}{c}{ 升学率 } & \multicolumn{3}{c}{ 就业、创业、其他情况率 } \\
\hline 对应函数 & \multicolumn{2}{c}{$\mathrm{C}$} & \multicolumn{3}{c}{$\mathrm{A} 、 \mathrm{~B} 、 \mathrm{D}$} \\
二级指标 & 本专业升学率 & 非本专业升学率 & 隐性就业率 & 失业率 & 就业率 & 创业率 \\
对应函数 & $\mathrm{C} 1$ & $\mathrm{C} 2$ & $\mathrm{D} 1$ & $\mathrm{D} 2$ & $\mathrm{~A}$ & $\mathrm{~B}$ \\
对应系数 & $\mathrm{K} 1$ & $\mathrm{~K} 2$ & $\mathrm{~K} 3$ & $\mathrm{~K} 4$ & 0 & 0
\end{tabular}

根据表 1、表 2、表 3 所示信息类人才专业实践评价指标，可以提出物联网工程专业人才的就业、创 业、升学方向专业实践评价标准, 如下: 


\section{$\mathrm{B}^{r}=\mathrm{N} 1 \times \mathrm{B} 1+\mathrm{N} 2 \times \mathrm{B} 2-\mathrm{N} 3 \times \mathrm{D} 1-\mathrm{N} 4 \times \mathrm{D} 2-0 \times \mathrm{A}-0 \times \mathrm{C}$ \\ $\mathrm{C}^{x}=\mathrm{K} 1 \times \mathrm{C} 1+\mathrm{K} 2 \times \mathrm{C} 2-\mathrm{K} 3 \times \mathrm{D} 1-\mathrm{K} 4 \times \mathrm{D} 2-0 \times \mathrm{A}-0 \times \mathrm{B}$}

其中, $A^{\prime} 、 B^{\prime}$ 和 $C^{\prime}$ 分别表示就业、创业、升学的有效性程度, 即人才培养中专业实践目标与就业、 创业、升学情况相一致的程度, 体现出该方向专业实践的有效性。A1、A2、A3、D1、D2 取值的不同, 将决 定 $\mathrm{A}^{\prime}$ 值的大小; B1、B2、D1、D2 取值的不同, 将决定 B' 值的大小; C1、C2、D1、D2 取值的不同, 将决 定 C' 值的大小; M1、M2、M3、M4、M5、N1、N2、N3、N4、K1、K2、K3、K4 表示各个函数变量对应的系数, 系数取值的不同, 将分别影响 $\mathrm{A}^{\prime} 、 \mathrm{~B}^{\prime}$ 值和 $\mathrm{C}^{\prime}$ 的大小。

当进行就业方向评价时, B、C 的函数变量对应的系数都取 0 , 即在统计就业方向专业实践效果时, 选 择创业和进行升学的毕业生不影响该方向的评价。同理, 但进行创业或升学方向评价时, 其他两个方向的 毕业生也不影响该方向的评价。 $A^{\prime} 、 B^{\prime}$ 和 $C^{\prime}$ 的值分别在较高时, 说明人才培养中该方向专业实践效果较 好; 对应值分别在过低时, 说明人才培养的缺失和不足, 需要对专业实践该方向内容进行及时调整。

\section{3 示例分析}

目前, 国内高校在推行 “ $3+1$ ” 人才培养模式和专业实践内容时, 实际操作中还没有针对创业方向开 展专业实践工作, 缺乏相关数据, 因此不对创业方向专业实践效果进行评价。以某高校物联网工程专业实 践的实际情况和数据为基础, 分别对就业和升学两个方向专业实践效果进行评价。

\section{1 评价结果}

参加就业方向的学生有 32 人, 其中 “双专就业” 人数为 11 人, “通专就业” 人数为 16 人, “其他就 业” 人数为 4 人, “失业” 人数为 1 人, 其他类型人数都为 0 人; 参加升学方向的学生有 20 人, 其中 “本 专业升学” 人数为 9 人, “非本专业升学” 人数为 2 人, “就业” 人数为 8 人, “隐性就业” 人数为 1 人 (准 备继续考研), 其他类型人数都为 0 人。

根据就业方向专业实践的实际情况，设定公式（1）中 M1、M2、M3、M4、M5 分别为 2.0、1.0、0.5、 1. 0、2.0, 将就业方向数据代入公式 (1), 得出评价结果如下:

$$
\mathrm{A}^{x}=2.0 \times \frac{10}{32}+1.0 \times \frac{17}{32}-0.5 \times \frac{4}{32}-1.0 \times \frac{0}{32}-2.0 \times \frac{1}{32}-0 \times \mathrm{B}-0 \times \mathrm{C}=
$$

根据升学方向专业实践的实际情况, 设定公式 (3) 中 K1、K2、K3、K4 分别为 2.0、1.0、1.0、2.0, 将升学方向数据代入公式 (3), 得出评价结果如下:

$$
\mathrm{C}^{x}=2.0 \times \frac{9}{20}+1.0 \times \frac{2}{20}-1.0 \times \frac{1}{20}-2.0 \times \frac{0}{20}-0 \times 8-0 \times \mathrm{B}=
$$

\section{2 结果分析}

对于就业方向专业实践效果评价结果, 公式 (1) 中 M1、M2、M3、M4、M5 的取值是根据对应 A1、A2、 A3、D1、D2 函数变量的含义确定的, 即认为 “双专就业率” 是评价就业方向专业实践效果好坏的最正向因 素, 而 “失业率” 则是评价就业方向专业实践效果好坏的最负向因素, 其余各项也对评价结果有着正向或 负向作用, 只是影响的幅度不同。通过 M1、M2、M3、M4、M5 的取值, 可以分析从 $A^{\prime}$ 的取值应该为 $[-2,2]$, 通常情况下应该处于 1 左右。所以 $\mathrm{A}^{\prime}$ 计算结果 1.03125 , 符合正常取值范围, 说明人才培养中就业方向 专业实践效果比较合适。同理, 对于升学方向专业实践效果评价结果, $C^{\prime}$ 的取值也应该为 $[-2,2]$, 通常 
情况下应该处于 1 左右。同时, 认为 “本专业升学率” 是评价升学方向专业实践效果好坏的最正向因素, 而 “失业率” 则是评价就业方向专业实践效果好坏的最负向因素，其余各项也对评价结果有着正向或负向 作用, 只是影响的幅度不同。所以 $\mathrm{C}^{\prime}$ 计算结果 0.9 , 也符合正常取值范围, 不过较就业方向专业实践效 果较差。从升学方向的实践情况和数据来看, 应该进一步加强升学方向的 “本专业升学” 人数和 “非本专 业升学” 人数, 减少 “就业” 人数。

\section{4 结论}

专业实践作为实践教学体系的核心内容, 在国内高校推行的 “ $3+1$ ” 人才培养模式中占据重要地位。 通过最后一年的专业实践开展，能够为毕业生未来发展提供坚实的实践基础。目前 “ $3+1$ ” 物联网工程专 业人才培养模式中就业、创业、升学三个不同方向专业实践, 都没有相应的专业实践效果量化评价指标。 无法评价专业实践内容是否合适和分析潜在的缺失，使得专业实践内容的制定和调整缺乏依据。针对这一 问题，提出了物联网工程专业具体的专业实践评价指标体系，解决专业实践效果缺乏评价指标问题。

\section{5 致谢}

本文研究得到通讯作者韩宝平老师的大力帮助，本文为 2016 年北京市教委科研计划一般项目 (PXM2016 014207 000008) 的阶段性成果之一。

\section{Acknowledgement:}

Corresponding author is Han Baoping. The authors would like to acknowledge the supports provided by 2016 General Scientific Research Project of Beijing Municipal Education Commission (PXM2016_014207_000008).

\section{参考文献:}

[1] 程绝林．基于" $3+1$ "人才培养模式改革的教学管理创新．教育艺术，2008（6）：23-25

[2] 李尧，等. 应用型高校 “ $3+1$ ” 人才培养模式的实践探索．教育与职业，2010（26）：24-25

[3] Knox A B. The Continuum of Professional Education and Practice. New Directions for Adult \& Continuing Education, 2000 (86) : 13-22

[14Shaw S F, Mcguire J M, Madaus J W. Standards of Professional Practice. Journal of Postsecondary Education \& Disability, 1997 (12) : 26-35

[5] Hager P. Professional Practice in Education: Research and Issues. Australian Journal of Education, 1996 , 40 (3) : $235-247$

[6] 吴春祥，骆剑锋，张智燕. 广东高校物联网专业建设的思考. 东莞理工学院学报，2014，（3）：P117-120

[7] 顾秉林，等．创新性实践教育一一基于高水平学科建设的创新人才培养之路 [J]．清华大学教育研究，2010，31 (1) : $1-5$

[8] Bashar A, Siddeeq Y. Impact of Different Training Mode on Adaptive Equalization Techniques for MIM0-OFDM System. Communications on Applied Electronics (CAE). 2017, 7 (2): 29-33.

[9] Bright S, Selemani C, Bright S, etc al. The Development of Speech-Language Pathology in Zambia: A Reflection on the Current Landscape and Two Contrasting Training Models. Perspectives of the ASHA Special Interest Groups, 2017，2: 63-72

[10］石恒华，等. “ $3+1$ ” 计算机人才培养模式中专业实践评价指标体系研究. 第二届人文科学、管理和教育技术国际 学术会议. 2017年9月. 


\section{References}

[1] Cheng Yan-lin. Based on "3+1" Talent Training Mode Reform of Teaching Management Innovation. Art of Education, 2008 (6): 23-25

[2] Li Yao, et al. Practical Exploration of "3+1" Talents Training Mode in Applied Colleges. Education and Profession, 2010 (26): 24-25

[3] Knox A B. The Continuum of Professional Education and Practice. New Directions for Adult \& Continuing Education, 2000 (86) :13-22

[4] Shaw S F, Mcguire J M, Madaus J W. Standards of Professional Practice. Journal of Postsecondary Education \& Disability, 1997 (12) :26-35

[5] Hager P. Professional Practice in Education: Research and Issues. Australian Journal of Education, 1996 , 40 (3) :235-247

[6] Wu Chun-xiang, Luo Jian-feng, Zhang Zhi-yan. Reflections on IoT Major Construction in Colleges and Universities in Guangdong. Journal of Dongguan University of Technology, 2014,(3): 117-120.

[7] Gu Binglin, et al. Innovative Practical Education -- The Way to Cultivate Creative Talents based on High-level Discipline Construction. Tsinghua University Education Research, 2010, 31 (1): 1-5

[8] Bashar A, Siddeeq Y. Impact of Different Training Mode on Adaptive Equalization Techniques for MIMO-OFDM System. Communications on Applied Electronics (CAE). 2017,7(2): 29-33.

[9] Bright S, Selemani C, Bright S, etc al. The Development of Speech-Language Pathology in Zambia: A Reflection on the Current Landscape and Two Contrasting Training Models. Perspectives of the ASHA Special Interest Groups, 2017, 2: 63-72

[10] Shi, Henghua, et al. Research on the Professional Practice Evaluation Index System of the Information Talents Training Mode. Second International Conference on Human Science, Management and Education Technology. In Press, Sep. 2017 